\title{
Bond strength and micromorphology of resin-dentin interface of etch-and-rinse dentin bonding agents after 1-year of water storage
}

\author{
Adriana Oliveira Carvalho ${ }^{1}$, Renata Bacelar-Sá ${ }^{2}$, Osvaldo Wodevotzky Jr. ${ }^{3}$, Gláucia Maria Bovi Ambrosano ${ }^{4}$, \\ Pascal Christophe Magne ${ }^{5}$ and Marcelo Giannini ${ }^{2^{*}}$
}

\section{*Correspondence:}

giannini@fop.unicamp.br

2 Department of Restorative

Dentistry, Piracicaba Dental

School, State University

of Campinas, Av. Limeira, 901,

Piracicaba, SP 13414-903,

Brazil

Full list of author information is available at the end of the article

\begin{abstract}
This study compared the microtensile bond strength (BS) and the micromorphology of resin-dentin interface (MI) of a conventional adhesive to two-steps etch-and-rinse bonding agents after 1 year of water storage. Twenty-eight human third molars were used ( $n=7$ ). Teeth were divided into four groups (GCB: Gluma Comfort Bond; OPB: OptiBond FL; OCB: One Coat Bond SL; PUB: Peak Universal Bond). Specimens were tested in tension after $24 \mathrm{~h}$ or 1 year of water storage. Dentin BS strength data were analyzed by split-plot two-way ANOVA followed by Tukey-Kramer tests $(a=0.05)$. Water-storage for 1 year significantly decreased BS for OCB; however, no significant difference was noted between OCB and GCB and PUB adhesives after 1 year of water-storage. OPB showed the highest BS values at both storage times. All adhesives formed a hybrid layer with resin tags, and both interfacial structures were maintained after 1 year. However, degradation signals within interfacial structures were observed only for the adhesive with a bond strength reduction. BS test showed that only one adhesive declined after 1 year of water storage. The degradation of some structures of the interface collaborated this finding. The classic three-step etch-and-rinse (OPB) presented higher values of bond strength than GCB and OCB after 1 year, but it was not statistically different from PUB.
\end{abstract}

Keywords: Bonding agents, Dentin, Bond strength, Scanning electron microscopy

\section{Background}

The three-step, etch-and-rinse adhesives have been considered "gold standard" in terms of bonding durability and strength. These adhesive systems consist of phosphoric acid etching, priming and hydrophobic resin application before light-activation. Each step has a specific function, which avoids some problems related to simplified adhesives, such as phase separation, low degree of conversion, lack of dentin sealing and poor hybridization [1-5]. Although they are proven to perform better, some clinicians prefer simplified materials for restorative procedures in attempt to save chair-time [6-8].

The two-step etch-and-rinse adhesives were the first simplified bonding agents, which are used following the acid etching step. They are a combination of primer and bonding

(c) 2016 The Author(s). This article is distributed under the terms of the Creative Commons Attribution 4.0 International License (http://creativecommons.org/licenses/by/4.0/), which permits unrestricted use, distribution, and reproduction in any medium, provided you give appropriate credit to the original author(s) and the source, provide a link to the Creative Commons license, and indicate if changes were made. 
resin in a single bottle that produces a complex solution, containing hydrophilic and hydrophobic monomers [9]. Later on, the self-etching adhesives also become popular in restorative dentistry as simplified materials. For self-etching materials, the simplification means avoiding phosphoric acid etching and moisture control before adhesive application [10].

The effectiveness of simplified adhesives has been questioned according to the results of nanoleakage, permeability and bond strength studies [11, 12]. A combination between hydrophilic monomers from primer solution and hydrophobic monomers from bonding resin has produced in some cases an acidic and hydrophilic bonding agent. The longevity of the resin-dentin interface formed by simplified adhesives depends on the quality of adhesive monomers used, acidity and the hydrophilicity levels of primer/adhesive solutions $[7,13]$.

This study compared the dentin bond strength and interfacial micromorphology of a conventional adhesive system to simplified etch-and-rinse adhesives after water storage for 1 year. The null hypothesis was that (1) the various dentin adhesives would have the same bond strength for a given storage time and that (2) the water storage does not influence the bond strength and the interfacial micromorphology regardless of the category of adhesive systems tested.

\section{Methods}

\section{Specimen preparation}

Twenty-eight caries-free human third molars were used in this study. Teeth were stored in $0.5 \%$ thymol solution for no more than 3 months. These teeth were obtained under a protocol approved by the review board of the Institutional Ethics Committee (\#146/2010).

The teeth were sectioned $2 \mathrm{~mm}$ beneath the cemento-enamel junction with a diamond saw (Buehler, Lake Bluff, IL, USA) under water-cooling to remove the roots. Their occlusal enamel surfaces were wet abraded with silicon carbide paper (180-grit) using a polishing machine (APL-4, Arotec, Cotia, SP, Brazil) to expose a flat dentin surface with a residual thickness of $4-5 \mathrm{~mm}$. The dentin surfaces were then polished with 600 -grit silicon carbide paper under water for $10 \mathrm{~s}$ to create standardized smear layer. The teeth were randomly divided into four groups $(\mathrm{n}=7)$.

\section{Experimental design and bonding procedures}

Four commercially available etch-and-rinse adhesives were used in this study. A threesteps etch-and-rinse adhesive (Optibond FL, Kerr Corp., Orange, CA, USA) was used as a control. Other three two-steps etch-and-rinse adhesives (Gluma Confort Bond, Heraeus Kulzer GmbH, Hanau, Germany; One Coat Bond SL, Coltène/Whaledent AG, Altstätten, Switzerland and Peak Universal Bond, Ultradent Products Inc., South Jordan, UT, USA) were compared to the control. The chemical composition and lot number of each adhesive are summarized in Table 1 .

The dentin surfaces were acid etched for $15 \mathrm{~s}$ with $37 \%$ phosphoric acid and rinsed for $30 \mathrm{~s}$ with water. Excess water was removed by air-drying for $5 \mathrm{~s}$ and absorbent paper (Kleenex Classic, Kimberly-Clark, Suzano, SP, Brazil), leaving the dentin surface 
Table 1 Composition of adhesive systems used in this study (information supplied by the MSDS of each manufacturer) and their batch number

\begin{tabular}{|c|c|c|}
\hline Adhesive system & Composition & Lot number \\
\hline $\begin{array}{l}\text { Gluma Comfort Bond } \\
\text { + Desensitizer }\end{array}$ & $\begin{array}{l}\text { Phosphoric acid: } 35 \text { \% } \\
\text { Adhesive: 2-hydroxyethyl methacrylate, poly(methacrylic- } \\
\text { oligo-acrylic acid), 4-methacryloxyethyltrimellitic acid } \\
\text { anhydride, glutaraldehyde, ethanol }\end{array}$ & 010111 \\
\hline Optibond FL & $\begin{array}{l}\text { Phosphoric acid: } 37.5 \% \\
\text { Primer: 2-hydroxyethyl methacrylate, glycerol phosphate } \\
\text { dimethacrylate, mono-2-methacryloyloxyethyl phthalate, } \\
\text { water, ethanol } \\
\text { Adhesive resin: bisphenol A diglycidyl methacrylate, } \\
\text { 2-hydroxyethyl methacrylate, glycerol dimethacrylate, } \\
\text { filler (fumed SiO2, barium aluminoborosilicate, Na2SiF6) }\end{array}$ & 3437986 \\
\hline One Coat Bond SL & $\begin{array}{l}\text { Phosphoric acid: } 35-40 \% \\
\text { Adhesive: } 2 \text {-hydroxyethyl methacrylate, hydroxypropyl } \\
\text { methacrylate, methacrylate modified polyacrylic acid, } \\
\text { urethane dimethacrylate, glycerol dimethacrylate, amor- } \\
\text { phous silicic acid, water, initiators and stabilizers }\end{array}$ & 0175578 \\
\hline Peak Universal Bond & $\begin{array}{l}\text { Phosphoric acid: } 35 \% \\
\text { Adhesive: } 2 \text {-hydroxyethyl methacrylate, methacrylic acid, } \\
\text { ethyl alcohol, chlorhexidine }(0.2 \%)\end{array}$ & PKCX C42MD \\
\hline
\end{tabular}

visibly moist. Etch-and-rinse adhesives were applied according to the manufacturer's instructions.

After application of adhesive, $6 \mathrm{~mm}$ high resin composite blocks were incrementally built-up over dentin using three 2-mm-thick layers of composite resin (shade A2, Filtek Supreme, 3M ESPE). A light-curing unit (Valo, Ultradent Products Inc.) with an output of $885 \mathrm{~mW} / \mathrm{cm}^{2}$ was used to polymerize the adhesives and the composite.

\section{Microtensile bond strength test}

Restored teeth were stored in distilled water at $37^{\circ} \mathrm{C}$ for $24 \mathrm{~h}$ and then vertically, serially sectioned into 1.0-mm-thick slabs, using a diamond blade (Buehler, Lake Bluff, IL, USA). Each slab was further sectioned perpendicularly to produce micro-beams (specimens) of approximately $1 \mathrm{~mm}^{2}$ in cross section. Four of the bonded sticks were immediately tested and the other four were tested after 1 year of storage in distilled water at $37^{\circ} \mathrm{C}$. Each bonded stick was attached to the grips of a microtensile testing device with cyanoacrylate glue (Super Bonder gel, Henkel/Loctite, Diadema, SP, Brazil) and tested in tension in a universal testing machine (EZ Test, Shimazu, Kyoto, Japan) at a crosshead speed of $1 \mathrm{~mm} / \mathrm{min}$ until failure. After testing, the specimens were removed from device and the cross-sectional area was measured to the nearest $0.01 \mathrm{~mm}$ with a digital caliper (mod. 727-/150, Starret; Itu, SP, Brazil). The cross-sectional area of each specimen was divided by the peak tensile load at failure to calculate stress at fracture (MPa). A single failure stress value was then calculated for each tooth and time by averaging the values of eight sticks from that tooth (four specimens from the same tooth for each evaluation time). The bond strength data were analyzed using a two-way analysis of variance (ANOVA) to determine the effect of adhesive systems and storage times and their interaction on bond strength. Tukey-Kramer test was used to detect differences among 
experimental groups. All statistical testing (SAS Institute Inc., Singapore) was performed at a preset alpha of 0.05 .

\section{Scanning electron microscopy (SEM) of bonded interfaces}

Four specimens of each tooth were used in this part of the study. Two were analyzed immediately, while other two were stored in water for 1 year before analyzing. The specimens were embedded in epoxy resin (Buehler, Lake Bluff, IL, USA) and polished with $\mathrm{Al}_{2} \mathrm{O}_{3}$ (800-, 1000- and 1200-grits), followed by diamond pastes $(6,3,1$ and $0.25 \mu \mathrm{m})$. Samples were rinsed and polishing debris was ultrasonically removed during 5-min cleaning after each polishing step. After polishing, specimens were etched with $50 \%$ phosphoric acid for $15 \mathrm{~s}$, washed, and treated with $0.1 \%$ with $\mathrm{NaOCl}$ for $10 \mathrm{~min}$. Slabs were dehydrated in ascending ethanol concentrations (25, 50, 75, 95 and $100 \%)$ and immersed in hexamethydisilazane for $10 \mathrm{~min}$. After drying overnight (at $37^{\circ} \mathrm{C}$ ), embedded specimens were mounted in aluminum stubs, sputter coated with gold (MED 010, Balzers; Balzer, Liechtenstein) and examined by a single individual using a SEM (Leo 435 VP, Leo Electron Microscopy Ltd, Cambridge, UK). Representative area of the adhesivedentin interfaces were photographed at $2000 \times$.

\section{Results}

Table 2 shows the bond strength means $( \pm \mathrm{SD})$ for the adhesive systems after $24 \mathrm{~h}$ and 1 year of water storage. The two-way ANOVA showed statistically significant differences for both factors (adhesive system and storage time) $(\mathrm{p}<0.0001)$ and significant interaction between them $(\mathrm{p}=0.0112)$.

The 1-year storage decreased the dentin bond strength only for One Coat Bond SL $(\mathrm{p}<0.05)$. However, this adhesive originally (at $24 \mathrm{~h}$ ) did not show significant difference with Optibond FL ( $\mathrm{p}>0.05$ ), which presented higher bond strength than those obtained for Gluma Comfort Bond and Peak Universal Bond at $24 \mathrm{~h}(\mathrm{p}<0.05)$. Optibond FL showed higher dentin bond strength than Gluma Comfort Bond and One Coat Bond SL after storage for 1 year $(\mathrm{p}<0.05)$, but it was not statistically different from Peak Universal Bond. Gluma Comfort Bond, Peak Universal Bond and One Coat Bond SL adhesives presented no significant difference among them $(\mathrm{p}>0.05)$.

Table 2 Means ( \pm standard deviation) of dentin bond strength of adhesive systems tested in this study (MPa)

\begin{tabular}{lll}
\hline Adhesive system & \multicolumn{1}{l}{ Time } & \\
\cline { 2 - 3 } & $\mathbf{2 4 \mathbf { h }}$ & $\mathbf{1}$ year \\
\hline Gluma Comfort Bond & $50.4(8.4) \mathrm{Ab}$ & $42.7(13.2) \mathrm{Ab}$ \\
Optibond FL & $67.7(5.1) \mathrm{Aa}$ & $61.6(6.8) \mathrm{Aa}$ \\
One Coat Bond SL & $59.4(8.2) \mathrm{Aab}$ & $35.7(9.0) \mathrm{Bb}$ \\
Peak Universal Bond & $51.2(10.0) \mathrm{Ab}$ & $46.2(12.5) \mathrm{Aab}$
\end{tabular}

Values of groups having similar letters were not significantly different $(p=0.05)$. (uppercase letters $=$ rows; lowercase letters = column) 
Representative areas of resin-dentin interfaces are showed in the Fig. 1a, b. All adhesives formed the hybrid layer and resin tags in dentinal tubules. Some signals of resin tags degradation can be observed in the Fig. If and its hybrid layer seemed more porous after storage for 1 year.
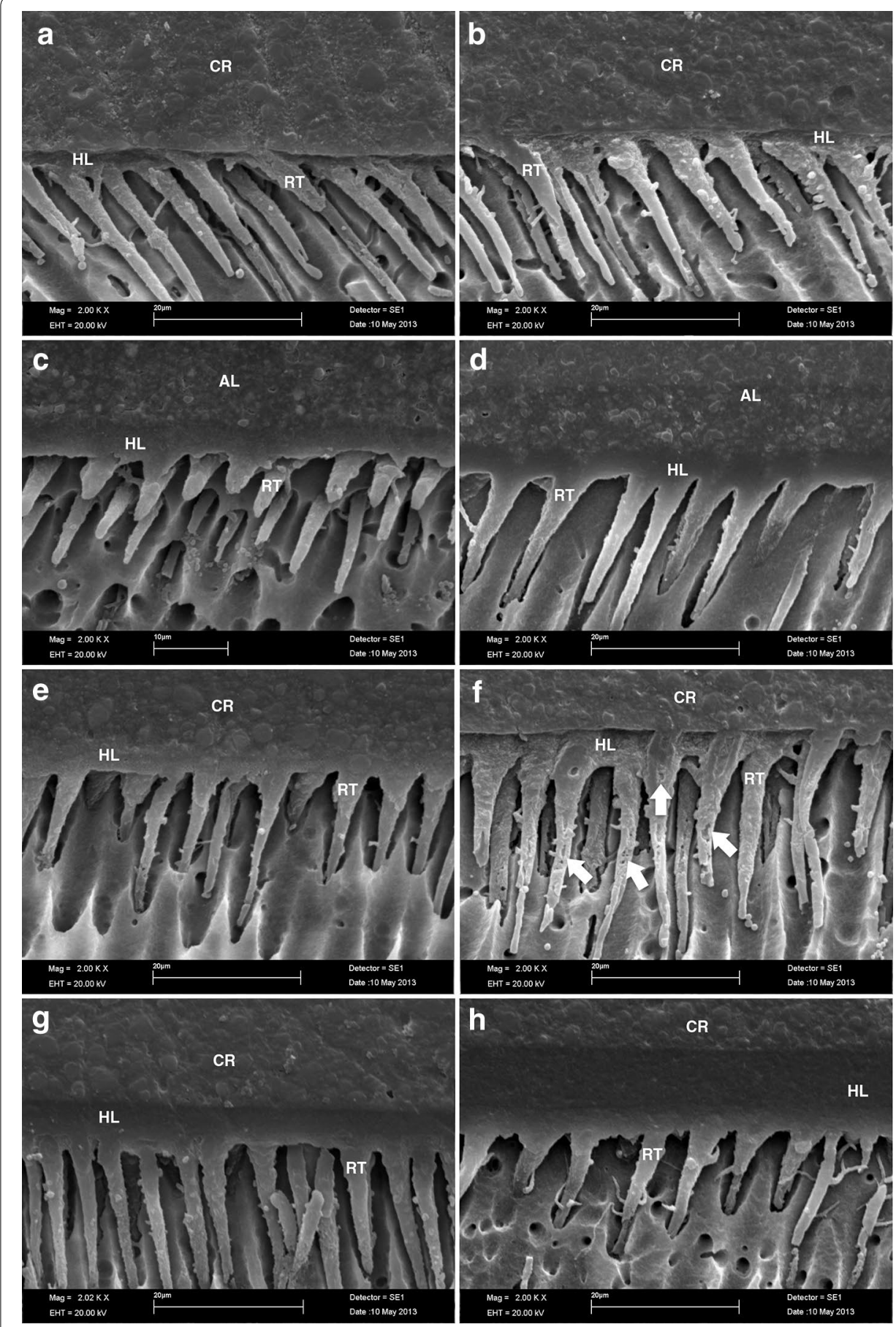
(See figure on previous page)

Fig. 1 a Representative SEM micrograph of the resin-dentin interface formed by the Gluma Comfort Bond + Desensitizer two-step etch-and-rinse adhesive ( $\times 2000$ magnification). Samples were storage in water for $24 \mathrm{~h}$ (CR composite resin, $H L$ hybrid layer, $R T$ resin tag). b Representative SEM micrograph of the resin-dentin interface formed by the Gluma Comfort Bond + Desensitizer two-step etch-and-rinse $(\times 2000$ magnification). Samples were storage in water for 1 year (CR composite resin, HL hybrid layer, RT resin tag). c Representative SEM micrograph of the resin-dentin interface formed by the Optibond FL three-step etch-and-rinse adhesive ( $\times 2000$ magnification). Samples were storage in water for $24 \mathrm{~h}$ (AL adhesive layer, $H L$ hybrid layer, $R T$ resin tag). d Representative SEM micrograph of the resin-dentin interface formed by the Optibond FL three-step etch-and-rinse adhesive ( $\times 2000$ magnification). Samples were storage in water for 1 year (AL adhesive layer, HL hybrid layer, RT resin tag). e Representative SEM micrograph of the resin-dentin interface formed by the One Coat Bond SL two-step etch-and-rinse (×2000 magnification). Samples were storage in water for $24 \mathrm{~h}$ (CR composite resin, HL hybrid layer, $R T$ resin tag). f Representative SEM micrograph of the resin-dentin interface formed by the One Coat Bond SL two-step etch-and-rinse ( $\times 2000$ magnification). Samples were storage in water for 1 year. Arrows show porosities in resin tags (RT) (CR composite resin, $H L$ hybrid layer). $\mathbf{g}$ Representative SEM micrograph of the resin-dentin interface formed by the Peak Universal Bond two-step etch-and-rinse ( $\times 2000$ magnification). Samples were storage in water for $24 \mathrm{~h}$ (CR composite resin, HL hybrid layer, RT resin tag). h Representative SEM micrograph of the resin-dentin interface formed by the Peak Universal Bond two-step etch-and-rinse ( $\times 2000$ magnification). Samples were storage in water for 1 year (CR composite resin, HL hybrid layer, RT resin tag)

\section{Discussion}

The first part of the hypothesis can be rejected since the three-step etch-and-rinse adhesive performed better than the others. The second part of the null hypothesis stating that the water storage did not influence the bond strength and the interfacial micromorphology of the adhesive was partially accepted since a two-step etch-and-rinse was affect by storage for 1 year. The bond strength reduction for One Coat Bond SL was approximately $40 \%$, while other adhesives showed 9-15\% of bond strength reduction, which were not statistically significant. Although the bond strength reduction was reported, this mean value $(35.7 \pm 9.0 \mathrm{MPa})$ was not significant different from two other two-step etch-and-rinse adhesives (Gluma Comfort Bond: $42.7 \pm 13.2 \mathrm{MPa}$ and Peak Universal Bond: $46.2 \pm 12.5 \mathrm{MPa})$.

One Coat Bond SL is a filled adhesive and consists of 53 \% hydrophilic monomers and $41 \%$ hydrophobic monomers. It contains $5 \%$ of fumed silica and the same concentration of water. This adhesive did not contain acetone or any type of alcohol as organic solvent, which is rare among bonding agents. The functional methacrylates monomers (HEMA and hydroxypropyl methacrylate) with hydroxy groups belongs the hydrophilic part of One Coat Bond SL, therefore compatible with water [14]. The absence of an organic solvent might reduce the infiltration rate of adhesive monomers into demineralized dentin, which compromise the longevity of dentin bonding as observed in this study. The methacrylate modified polyacrylic acid (MMPA) is also a hydrophilic component and the carbon acid side group is used to chemically react with calcium ions and collagen network present in dental tissues. The difunctional monomers, urethane dimethacrylate and glycerol dimethacrylate, and the methacrylic ester side groups of MMPA are used to form polymer network after light-activation [9].

Gluma Comfort Bond also presents functional (adhesion promoter), hydrophilic and hydrophobic monomers. They are 4-META, HEMA and methacrylic-oligo-acrylic acid, respectively. This adhesive contains ethanol as the organic solvent and glutaraldehyde as a desensitizing agent. Glutaraldehyde is also a cross-linker agent, which is able to improve the mechanical properties of collagen fibrils and their resistance against 
degradation, increasing the longevity of bonding, as observed in this study $[15,16]$. No bond strength reduction was observed for Gluma Comfort Bond. The hybrid layer was thin when compared to other products and no change was noted for interfacial micromorphology after 1 year in water.

No changes in bond strength and interfacial micromorphology were also observed for Peak Universal Bond. This adhesive is an alcoholic solution containing HEMA and methacrylic acid monomers. It is a multi-mode adhesive, i.e., it can be used in etch-and-rinse and/or self-etch modes for enamel and/or dentin bonding. It was selected the etch-andrinse mode to compare with other two etch-and-rinse adhesives (Gluma Comfort Bond and One Coat Bond SL). The chlorhexidine solution has been added to preserve the dentin bonding and reduce collagen fibrils degradation. Studies have shown that dentin collagen degradation activity can be reduced using chlorhexidine application after acid etching [17-19]. However, there is no in vitro study or clinical trial that evaluated the use of $0.2 \%$ chlorhexidine incorporated into adhesive solution and its effect on dentin bonding.

The three-step etch-and-rinse Optibond FL was used as a control group, since it is considered the gold standard in terms of bonding durability [3]. Hydrophilic and hydrophobic monomers are presented in different bottles and are applied separately, which improve the quality of bonding. 2-hydroxyethyl methacrylate, glycerol phosphate dimethacrylate, Phthalic acid monomethacrylate, ethyl alcohol and water are the components of the Primer, while Bonding Resin contains uncured methacrylate ester monomers, 2-hydroxyethyl methacrylate, TEG-DMA and filler particles. The hydrophobic monomers applied over the primed dentin reduce primer hydrophilicity penetrated into dentin and ensure high degree of conversion of monomeric components present in resin-dentin interface, which improves the quality and longevity of dentin bonding by reducing the degradation rate of hydrophilic adhesive monomers [7]. After 1 year of water storage, the dentin bond strength was maintained without significant difference from the initial evaluation and in both evaluation periods it showed higher bond strength.

All adhesives form hybrid layer and long resin tags [20], however, the hybrid layer thickness varied. The Optibond FL and Peak Universal Bond (Fig. 1c, d, g, h) showed the thickest hybrid layers (approximately 5 microns) and only the Optibond FL formed the adhesive layer, because of the "bonding resin" (or hydrophobic monomer) application, which is the third step. The adhesive layer formed by hydrophobic monomer contains fumed $\mathrm{SiO}_{2}$, barium aluminoborosilicate and $\mathrm{Na}_{2} \mathrm{SiF}_{6}$ as filler particles, which had irregular and spherical shapes and formed radiopaque thicker layer than hybrid layer. For the other adhesives is it possible identifying the composite resin, which presents spherical agglomerate of silica nanocluster. These differences did not affect the dentin bond strength, since the 3-step etch-and-rinse Optibond FL was not significant different from One Coat Bond SL at $24 \mathrm{~h}$ and Peak Universal Bond after storage for 1 year. Some monomer degradation signs were present in the resin tags and hybrid layer formed by One Coat Bond SL. Resin tags had some defects and were not intact, while the hybrid layer seemed porous.

\section{Conclusions}

The present study indicates that the dentin bond strengths of conventional, three-step etch-and-rinse adhesive system (Optibond FL) and simplified etch-and-rinse adhesives (Gluma Comfort Bond and Peak Universal Bond) is unaffected by water storage 
for 1 year. Conversely, the bond strength of another simplified, two-step etch-and-rinse adhesive (One Coat Bond SL) declined after 1 year of water storage and the degradation of some structures of the interface collaborated this finding.

\section{Authors' contributions}

AOC drafting of manuscript and data acquisition of bond strength. RB Images acquisition of interfacial micromorphology. OW teeth and specimen preparations. GMBA study design and statistical analysis. PCM, MG study conception and design, and analysis and interpretation of data. All authors read and approved the final manuscript.

\section{Author details}

${ }^{1}$ Department of Dentistry, State University of Southern Bahia, Jequié, BA, Brazil. ${ }^{2}$ Department of Restorative Dentistry, Piracicaba Dental School, State University of Campinas, Av. Limeira, 901, Piracicaba, SP 13414-903, Brazil. ${ }^{3}$ São Paulo Dental Association-Limeira Division, Limeira, SP, Brazil. ${ }^{4}$ Department of Social Dentistry, Piracicaba Dental School, State University of Campinas, Piracicaba, SP, Brazil. ${ }^{5}$ Department of Restorative Sciences, Ostrow School of Dentistry, University of Southern California, Los Angeles, CA, USA.

\section{Acknowledgements}

This study was supported by grants from The National Council for Scientific and Technological Development (CNPq, Brazil, \# 307217-2014-0) and Coordination for the Improvement of Higher Education Personnel (CAPES, Brazil, \# 1777-2014).

\section{Competing interests}

There are non-financial competing interests (political, personal, religious, ideological, academic, intellectual, commercial or any other) to declare in relation to this manuscript.

Received: 21 June 2016 Accepted: 8 August 2016

Published online: 15 August 2016

\section{References}

1. Zhang Z, Beitzel D, Mutluay M, Tay FR, Pashley DH, Arola D. On the durability of resin-dentin bonds: identifying the weakest links. Dent Mater. 2015;31:1109-18.

2. Abedin F, Ye Q, Parthasarathy R, Misra A, Spencer P. Polymerization behavior of hydrophilic-rich phase of dentin adhesive. J Dent Res. 2015;94:500-7.

3. De Munck J, Van Landuyt K, Peumans M, Poitevin A, Lambrechts P, Braem M, Van Meerbeek B. A critical review of the durability of adhesion to tooth tissue: methods and results. J Dent Res. 2005;84:118-32.

4. Reis AF, Bedran-Russo AK, Giannini M, Pereira PN. Interfacial ultramorphology of single-step adhesives: nanoleakage as a function of time. J Oral Rehabil. 2007;34:213-21.

5. De Goes MF, Giannini M, Daronch M, Arrais CAG, Di Hipólito V, Rueggeberg FA. Bond strength and monomer conversion of bonding agents mixed with restorative composite prior to light exposure. J Adhes. 2007;83:105-16.

6. Pashley DH, Tay FR, Breschi L, Tjäderhane L, Carvalho RM, Carrilho M, Tezvergil-Mutluay A. State of the art etch-andrinse adhesives. Dent Mater. 2011;27:1-16.

7. Ozer F, Blatz MB. Self-etch and etch-and-rinse adhesive systems in clinical dentistry. Compend Contin Educ Dent. 2013;34:12-4.

8. Carvalho AO, Carrilho MRO, Rueggeberg FA, Ambrosano GMB, Giannini M. Bond strength, biaxial flexural strength and flexural modulus of dentin bonding systems exposed to water. Int J Adhes Adhes. 2014;49:109-14.

9. Van Landuyt KL, Snauwaert J, De Munck J, Peumans M, Yoshida Y, Poitevin A, Tezvergil-Mutluay A. Systematic review of the chemical composition of contemporary dental adhesives. Biomaterials. 2007;28:3757-85.

10. Van Meerbeek B, Yoshihara K, Yoshida Y, Mine A, De Munck J, Van Landuyt KL. State of the art of self-etch adhesives. Dent Mater. 2011;27:17-28.

11. Tay F, Pashley DH. Have dentin adhesives become too hydrophilic? J Can Dent Assoc. 2003;69:726-31.

12. Tay FR, Sano H, Carvalho RM, Pashley DH. An ultrastructural study of the influence of acidity of self-etching primers and smear layer thickness on bonding to intact dentin. J Adhes Dent. 2000;2:83-98.

13. Nawareg MM, Zidan AZ, Zhou J, Chiba A, Tagami J, Pashley DH. Adhesive sealing of dentin surfaces in vitro: a review. Am J Dent. 2015;28:321-32.

14. Nakabayashi N, Pashley DH. Hybridization of dental hard tissues. 1st ed. Tokyo: Quintessence Publishing Co; 1998.

15. Leme AA, Vidal CM, Hassan LS, Bedran-Russo AK. Potential role of surface wettability on the long-term stability of dentin bonds after surface biomodification. J Biomech. 2015;48:2067-71.

16. Kakaboura A, Rahiotis C, Thomaidis S, Doukoudakis S. Clinical effectiveness of two agents on the treatment of tooth cervical hypersensitivity. Am J Dent. 2005;18:291-5.

17. Abu Nawareg M, Elkassas D, Zidan A, Abuelenain D, Abu Haimed T, Hassan AH, Chiba A, BockT, Agee K, Pashley $\mathrm{DH}$. Is chlorhexidine-methacrylate as effective as chlorhexidine digluconate in preserving resin dentin interfaces? J Dent. 2016;45:7-13.

18. Gunaydin Z, Yazici AR, Cehreli ZC. In vivo and in vitro effects of chlorhexidine pretreatment on immediate and aged dentin bond strengths. Oper Dent. 2016:41:258-67.

19. Breschi L, Mazzoni A, Nato F, Carrilho M, Visintini E, Tjäderhane L, Ruggeri A Jr, Tay FR, Dorigo Ede S, Pashley DH. Chlorhexidine stabilizes the adhesive interface: a 2-year in vitro study. Dent Mater. 2010;26:320-5.

20. Marghalani HY, Bakhsh T, Sadr A, Tagami J. Ultramorphological assessment of dentin-resin interface after use of simplified adhesives. Oper Dent. 2015;40:E28-39. 